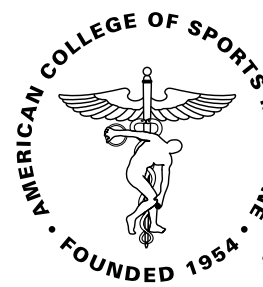

\title{
ACSM Clinician Profile
}

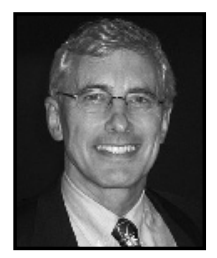

This month's ACSM Clinician Profile features William O. Roberts, MD, FACSM. Dr. Roberts has been a true pioneer in the field of primary care sports medicine, having been the first primary care physician elected president of ACSM. His contributions have been immense and particularly noteworthy in the areas of team physician education and medical care for endurance athletes. Dr. Roberts is currently an associate professor for the Department of Family Medicine and Community Health, Division of Sports Medicine, at the University of Minnesota; Phalen Village Clinic, Minneapolis; and the medical director for the Twin Cities Marathon. He is a Fellow of the American College of Sports Medicine and served as President from 2004 to 2005; a charter member of the American Medical Society of Sports Medicine; a founding member of the American Road Race Medical Society; and a member of the Sports Medicine Advisory Committees for the Minnesota State High School League and the USA Soccer Cup.

You have been an ACSM member since 1982, (and served as President in 2004-2005). How has ACSM grown and changed since you became a member? Since I joined ACSM, the organization has grown in membership numbers and in sports medicine stature. The focus has broadened from athlete care and performance, to the concept of exercise as medicine, and the science behind the health benefits of activity. With regard to physician members, the number of primary care physicians has increased, now matching the number of orthopedic surgeons who belong to the College. Our Annual Meeting has outgrown many of our previous convention sites and our flagship journal, Medicine \& Science in Sports o Exercise, has increased in stature as well. One thing that has remained constant since I joined is the unflagging love of science and medicine with regard to athletes and active people.

What was it like to be a clinician in the 1980 s as compared with today? Primary care sports medicine was starting to flourish in the 1980s when the foundation for the current fellowships and continuing medical education (CME) offerings was established through the efforts of ACSM members. The team physician education that started in that decade has improved and is readily available to interested clinicians through fellowships and CME. The sideline and training room atmosphere has moved from the assumption that sports medicine physicians are orthopedic surgeons to the utilization of primary care physicians as a part of the sports medicine team. The presence of certified athletic trainers at the high school level has increased the access and quality of sideline care.

How has membership in ACSM influenced your career? When I finished my residency, there were no fellowships for primary care in the area of sports medicine. ACSM was my sole source of up-to-date education on all facets of sports and activity science and medicine. The basic and applied science focus of ACSM built a foundation for my clinical education, and the ACSM education program that has expanded through the Team Physician Courses and our expanded offerings at the Annual Meeting. Although I am proud to have contributed to this effort, the early leg work was done by many who preceded me with the vision of bringing primary care, orthopedics, and other specialties together, utilizing the team concept to improve care for athletes and active people.

What is your best advice to other sports medicine clinicians? Exercise as medicine allows the application of our interest to all patients and makes for a simple patient philosophy that is best summed by the quote from George Sheehan, MD, "Every patient is an athlete." If you are interested in caring for athletes and active people, join ACSM and use it to get the information you need to deliver good care. The practice of sports medicine is more than hanging a shingle, and you will earn your patients with the time you spend "in the trenches" with athletes on the sidelines and at events.

Where do you see ACSM heading in the future? The current ACSM initiatives focusing on youth sports, exercise as medicine, and family fitness will help drive the clinical agenda. The College is poised to influence public policy on sports and activity with its strong science and clinical foundation. We are in a position to lead the way for team physicians and to guide the country toward an increase in activity-based lifestyle choices that can only benefit the nation's health.

Would you like to share anything else with the readers of Current Sports Medicine Reports? My career has been in family medicine, and I would not trade it for any other. My activities in sports medicine and with ACSM have been the "hobby" that has nourished and complemented my career beyond its usual boundaries and kept it young. If sports medicine excites you, enjoy the ride! 